\title{
0257 KEEP KIDS AWAY FROM TRACTORS CHILDHOOD AGRICULTURAL SAFETY PUBLIC AWARENESS CAMPAIGN
}

R M Fisher*, B C Lee Correspondence: National Farm Medicine Center, 1000 North Oak Avenue, Marshfield, WI 54449, USA

\subsection{6/ip.2010.029215.257}

The 2001 National Action Plan for Childhood Agricultural Injury Prevention in the United States, recommended that a network of child safety organisations should: develop a comprehensive, long-term, year-round public education campaign with messages about childhood agricultural injury prevention to be disseminated through a variety of media. In 2006, the Childhood Agricultural Safety Network (CASN), comprised of 14 national organisations, launched an initiative to reduce childhood agricultural injuries and fatalities through public awareness that influences social norms and adult behaviours. Based on national injury and death data, CASN focused on children and tractors. With core funding from National Institute for Occupational Safety and Health they adopted the principle that children under 12 years should never be on or near tractors. Participants solicited written and verbal perspectives regarding draft campaign materials from farm parents across the US feedback reports shaped the final poster images. In September 2006 the Keep Kids Away from Tractors campaign was launched. The primary poster depicted a grandfather and child on a tractor, with the slogan, Its easier to bury a tradition than a child. A Spanish version and two additional posters under the same theme were created and a website (www.childagsafety.org) was established. Data were collected on the Keep Kids Away from Tractors message in print publications during the first 12 months. Results revealed the campaign was featured in 115 publications including special interest magazines, listservs, websites and newspapers. As of January 2010, use of campaign materials by many safety organisations continues. 